\title{
Torque Ripple Suppression Method for BLDCM Drive Based on Four-Switch Three-Phase Inverter
}

\author{
Lei $\operatorname{Pan}^{\dagger}$, Hexu Sun ${ }^{*}$, Beibei Wang ${ }^{* *}$, Gang Su ${ }^{* *}$, Xiuli Wang ${ }^{* *}$, and Guili Peng ${ }^{* *}$ \\ ${ }^{\dagger * *}$ School of Control and Mechanical Engineering, Tianjin Chengjian University, Tianjin, China \\ ${ }^{*}$ Control Science and Engineering School, HeBei University of Technology, Tianjin, China
}

\begin{abstract}
A novel inverter fault-tolerant control scheme is proposed to drive brushless DC motor. A fault-tolerant inverter and its three fault-tolerant schemes (i.e., phase A fault-tolerant, phase B fault-tolerant, and phase C fault-tolerant) are analyzed. Eight voltage vectors are summarized and a voltage vector selection table is used in the control scheme to improve the midpoint current of the split capacitors. A stator flux observer is proposed. The observer can improve flux estimation, which does not require any speed adaptation mechanism and is immune to speed estimation error. Global stability of the flux observer is guaranteed by the Lyapunov stability analysis. A novel stator resistance estimator is incorporated into the sensorless drive to compensate for the effects of stator resistance variation. DC offset effects are mitigated by introducing an integral component in the observer gains. Finally, a control system based on the control scheme is established. Simulation and experiment results show that the method is correct and feasible.
\end{abstract}

Key words: DC offset, Fault-tolerant inverter, Flux observer, Stator resistance, Voltage space vector

\section{INTRODUCTION}

Brushless direct current motors (BLDCMs) are used extensively in servo systems and low-power drive systems because of their suitable features, such as simple construction, high reliability, light electromagnetic (EM) pollution, and high power density [1], [2].

Traditional BLDCM drives are based on a three-phase inverter. Although many modern drives offer a high degree of reliability, a three-phase inverter can develop various faults because of unexpected load conditions or erroneous operation. Kastha and Bose proposed a predicted fault performance method to determine stresses in the switching device and to evaluate satisfactory post-fault steady-state operating regions [3]. Khan and Rahman proposed a novel fault diagnostic and protection scheme for interior permanent-magnet synchronous motors that use wavelet packet transform and artificial neural network [4].

Manuscript received Nov. 8, 2014; accepted Feb. 9, 2015

Recommended for publication by Associate Editor Jung-Ik Ha.

†Corresponding Author: panlei4089@163.com

Tel: +86-22-2308-5137, Tianjin Chengjian University

*Control Science and Engineering School, HeBei University of

Technology, China

** School of Control and Mechanical Engineering, Tianjin Chengjian University, China
Four-switch, three-phase inverter (FSTPI) is widely considered as a fault reconfiguration topology for traditional six-switch inverters in fault-tolerant AC drive systems. However, the uncontrollable phase current causes an unsymmetrical voltage vector in FSTPI, and its waveform is more distorted than rectangular [5]. A new speed control method using the acceleration feed forward compensation is proposed [6] to improve the speed response characteristic for a four-switch three-phase BLDCM. The disturbance torque estimation method is adopted to improve the robustness of the method. However, this motor is economical and efficient only in certain conditions with light load, such as robot arm. Park used the space vector technique to decrease the torque ripple caused by unbalanced voltage and commutation ripple in FSTPI topology of BLDCMs [7]. The proposed control method is complicated, and it cannot attenuate the commutation torque ripples particularly at high speed. Lee et al. developed a novel DC-controlled PWM scheme [8]. This method uses two current sensors to lower the current ripple caused by an unbalanced voltage and decreases the commutation current ripple only at the low-speed region. However, their method does not cover the flux and torque performance. A novel approach to obtain ripple-free torque control with maximum efficiency 
based on the d-q-0 reference frame is presented [9]. The method optimizes the reference phase current waveforms that include three-phase unbalanced conditions, but it does not consider the DC bus voltage measurement error and stator resistance variation that impacts the estimation of $V_{d}$ and $V_{q}$.

A voltage space vector selection table based on eight voltage vectors is proposed to provide a basic condition for improving torque control and solving the abovementioned problems. A stator flux observer, DC voltage compensator, and stator resistance estimator are proposed to realize the precise torque control for BLDCM.

The theoretical operating principle of FSTPI for the three-phase BLDCM drive and the proposed control scheme is explained. The validity of the proposed method is verified and compared with traditional DC control methods [5] by experimental results.

\section{SYSTEM DESCRIPTION OF THE INVERTER TOPOLOGY AND PHASE CURRENT ANALYSIS}

Fig. 1 shows a healthy BLDCM drive configuration. The topology has three legs composed of switches $S_{1} S_{2}, S_{3} S_{4}$, and $S_{5} S_{6}$. Six isolating devices (i.e., fast active fuses denoted as $F_{a 1}, F_{b 1}, F_{c 1}, F_{a 2}, F_{b 2}$, and $F_{c 2}$ ) are used in each inverter leg, and three connecting devices (i.e., $T R_{a, b, c}$ or back-to-back connected SCRs) represented by triacs are used to modify the inverter circuit after fault isolation.

This topology can realize fault isolation for single switch open/short-circuit and single bridge arm open/short-circuit. The triac $T R_{a, b, c}$ is not triggered in the healthy mode, the drive system is in normal operation [10], [11], and the control method is based on the Zero-Crossing Detection of Back-EMF [11]. After the switch failure is detected [12], [13], the drive signal of the bridge arm is forbidden by the controller, and the reconfiguration is obtained using the triac $T R_{a, b, c}$ triggered to interconnect the $m_{j(j=1,2,3)}$ point to point $m_{0}$. Fig. 1(b) shows the inverter topologies obtained after that procedure is executed to compensate for the open/short-circuit of the switch $S_{1}$ or $S_{2}$.

Fig. 1(b) shows four possible switching patterns to generate three-phase currents. Fig. 2 shows the ideal switches; the four switching patterns are V(0101), V(1010), $\mathrm{V}(1001)$, and $\mathrm{V}(0110)$, where " 0 " means that the switch is turned off, and "1" means that the switch is turned on in the inverter. The free-wheeling diodes are also ignored. Two zero-voltage space vectors cannot supply the DC link to the load in the six-switch inverter, so no current flows through the load. The main difference between the four-switch and six-switch inverters is that one phase is always connected to the center tap of the split capacitors, so the current always flows through that phase even with voltage vectors V(0101) and V(1010) (Fig. 2). Under a balanced load condition with four-switch topology, no current flows through the phase connected to the midpoint of the split capacitors that use two

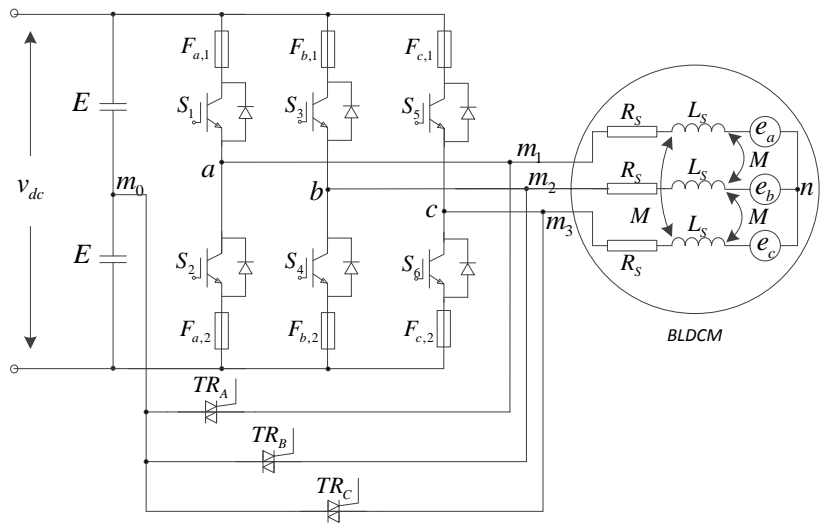

(a) Normal operation status.

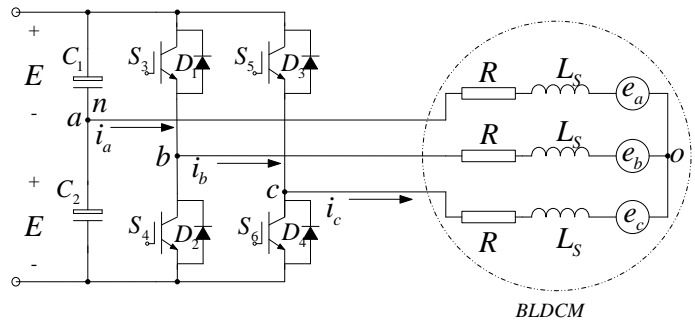

(b) Fault operation status.

Fig. 1. Basic configurations of the inverter BLDCM drive.

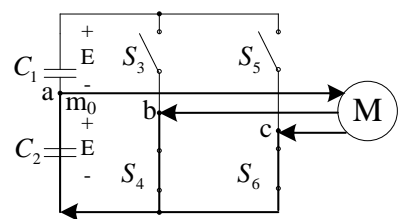

(a) $\mathrm{V}(0101)$

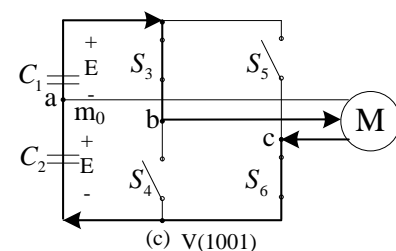

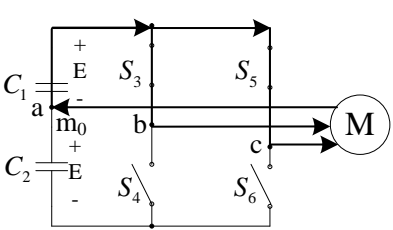

(b) $\mathrm{V}(1010)$

(d) V(0110)

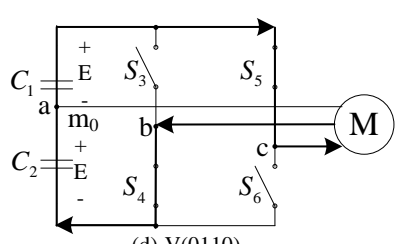

Fig. 2. Conventional four-switch voltage vector topology.

possible non-zero voltage vectors [i.e., $\mathrm{V}(1001)$ and $\mathrm{V}(0110)$ ], as shown in Fig. 2. When voltage vectors $\mathrm{V}(1001)$ and $\mathrm{V}(0110)$ are used and the load is incompletely balanced, only the resulting current of the other two phases flow through the phase connected to the midpoint of the split capacitors. This phenomenon causes a current and torque ripple. The simulation curve of the current under $1500 \mathrm{rpm}$ and $1 \mathrm{Nm}$ load using the four-switching pattern is shown in Fig. 3.

Three different cases can be found at the commutation moment as follows:

Case A: decaying current $\left(i_{d i}\right)$ vanishes at the same time as the rising current $\left(i_{r i}\right)$ reaches its final value $+\mathrm{I}$ in Fig. 4(a).

Case B: decaying current $\left(i_{d i}\right)$ vanishes before the rising current $\left(i_{r i}\right)$ reaches its final value $+\mathrm{I}$ in Fig. 4(b).

Case C: rising current $\left(i_{r i}\right)$ reaches the value $+\mathrm{I}$ before the decaying current $\left(i_{d i}\right)$ vanishes in Fig. $4(\mathrm{c})$. 

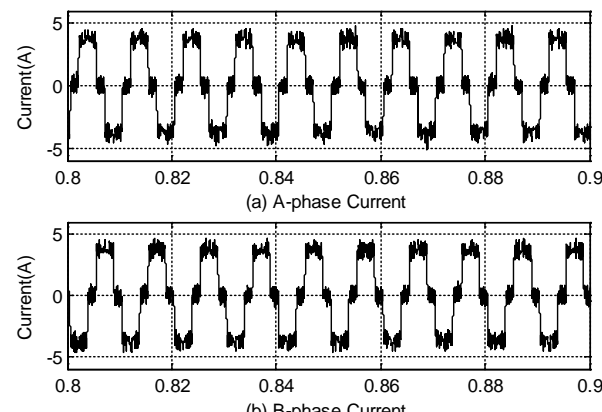

(b) B-phase Current

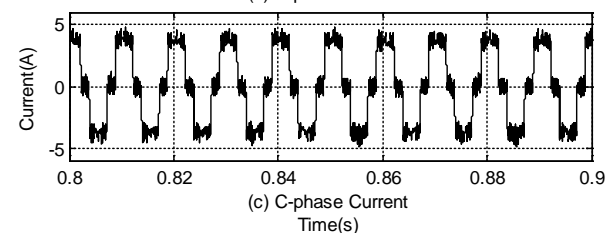

Fig. 3. Current curves that use a four-switching pattern under $1500 \mathrm{rpm}$ and $1 \mathrm{Nm}$ load.

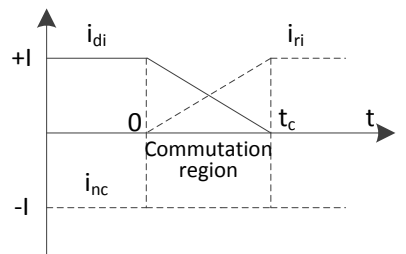

(a) Case $\mathrm{A}$

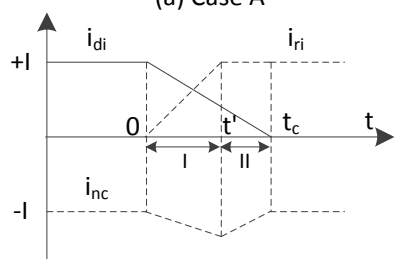

(c) Case C

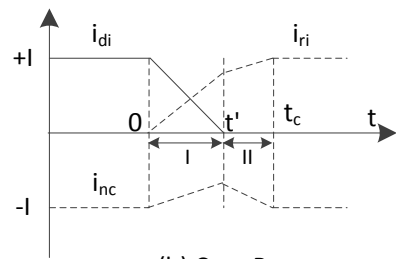

(b) Case B
Fig. 4. Current behavior patterns during commutation.

Current disturbance that flows through the phase connected to the midpoint of the split capacitors in cases B and C causes flux distortion and torque pulsation.

This paper presents a torque ripple suppression method to solve the abovementioned problems.

\section{TORQUE RIPPLE SUPPRESSION FOR FSTPI BLDCM DRIVE}

The typical mathematical model of a three-phase BLDCM is described as follows:

$$
\left[\begin{array}{l}
v_{a o} \\
v_{b o} \\
v_{c o}
\end{array}\right]=\left[\begin{array}{ccc}
R & 0 & 0 \\
0 & R & 0 \\
0 & 0 & R
\end{array}\right] \times\left[\begin{array}{l}
i_{a} \\
i_{b} \\
i_{c}
\end{array}\right]+\frac{d}{d t}\left[\begin{array}{ccc}
L_{s} & 0 & 0 \\
0 & L_{s} & 0 \\
0 & 0 & L_{s}
\end{array}\right]\left[\begin{array}{l}
i_{a} \\
i_{b} \\
i_{c}
\end{array}\right]+\left[\begin{array}{l}
e_{a o} \\
e_{b o} \\
e_{c o}
\end{array}\right]
$$

where $v_{a o}, v_{b o}$, and $v_{c o}$ are phase voltages; $R_{s}$ is the stator resistance; $L_{s}$ is the stator inductance $; i_{a}, i_{b}$, and $i_{c}$ are phase currents; and $e_{a o}, e_{b o}$, and $e_{c o}$ are phase back-EMFs.

Generating a 120 electrical degree current conduction is inherently difficult for the conventional four-switch topology because a BLDCM with non-sinusoidal back-EMF (i.e., trapezoidal) requires a quasi-square wave current profile to
TABLE I

Controlling Voltage Space Vector and Switch COMBINATION

\begin{tabular}{ccccc}
\hline & $\mathbf{V}_{\text {ao }}$ & $\mathbf{V}_{\text {bo }}$ & $\mathbf{V}_{\mathbf{c o}}$ & $\mathbf{S}_{\mathbf{1}} \mathbf{S}_{\mathbf{2}} \mathbf{S}_{\mathbf{3}} \mathbf{S}_{\mathbf{4}}$ (1:on; 0:off) \\
\hline $\mathrm{V}_{0}$ & $2 / 3 \mathrm{E}$ & $-1 / 3 \mathrm{E}$ & $-1 / 3 \mathrm{E}$ & 0101 \\
$\mathrm{~V}_{1}$ & $1 / 2 \mathrm{E}$ & 0 & $-1 / 2 \mathrm{E}$ & 0001 \\
$\mathrm{~V}_{2}$ & 0 & $\mathrm{E}$ & $-\mathrm{E}$ & 1001 \\
$\mathrm{~V}_{3}$ & $-1 / 2 \mathrm{E}$ & $1 / 2 \mathrm{E}$ & 0 & 1000 \\
$\mathrm{~V}_{4}$ & $-1 / 2 \mathrm{E}$ & 0 & $1 / 2 \mathrm{E}$ & 0010 \\
$\mathrm{~V}_{5}$ & 0 & $-\mathrm{E}$ & $\mathrm{E}$ & 0110 \\
$\mathrm{~V}_{6}$ & $1 / 2 \mathrm{E}$ & $-1 / 2 \mathrm{E}$ & 0 & 0100 \\
$\mathrm{~V}_{7}$ & $-2 / 3 \mathrm{E}$ & $1 / 3 \mathrm{E}$ & $1 / 3 \mathrm{E}$ & 1010 \\
\hline
\end{tabular}

generate constant output torque compared with that of a permanent magnet synchronous motor with sinusoidal back-EMF requiring sinewave current. These currents that have 120 electrical degrees of conduction period are synchronized with the flat portion of the corresponding phase back-EMFs, so a smooth EM torque can be obtained. Thus, only two phases conduct and the other phase is supposed to be inactive at any point.

Although four voltage vectors in a conventional four-switch inverter system are sufficient to control the three-phase AC motors using PWM techniques, these vectors cause a current ripple, as shown in Fig. 2. Thus, additional voltage vectors are required for BLDCM with the two-phase conduction mode to control the midpoint current of the split capacitors at a desired value, as shown in Fig. 2 [14]. Given that the conventional method cannot completely provide a two-phase conduction method, a new control scheme with new switching patterns should be developed such that only two of the three motor phases conduct.

A novel voltage vector selection look-up table is designed to obtain the operation switch modes in the four-switch BLDCM drive (Table I). The implementation of the voltage space vectors is depicted in Fig. 5(a), while the four-switch voltage vector topology is shown in Fig. 6.

Similarly, the voltage space vectors can be concluded with the fault occurrence in switches $S_{3}, S_{4}, S_{5}$, or $S_{6}$ as shown in Figs. 5(b) and 5(c).

The traditional direct current control (DCC) technique employs current hysteresis control [6], [15]. Six possible voltage space vectors of four-switch topology should be generally used in Table II, as shown in Figs. 6(a) to 6(f), similar to the six-switch version. However, two of the voltage vectors (i.e., $V_{2}$ and $V_{5}$ ) shown in Fig. 6 create problems in the current control. When these vectors are directly used in the voltage vector selection table (Table II), the back-EMF of the uncontrolled phase (Phase A) generates an undesired current, so distortions occur in each phase current. Thus, an undesired EM torque is inevitable. A special switching pattern should be adapted when the rotor position is in Sectors 2, 3, 6, and 7 . 


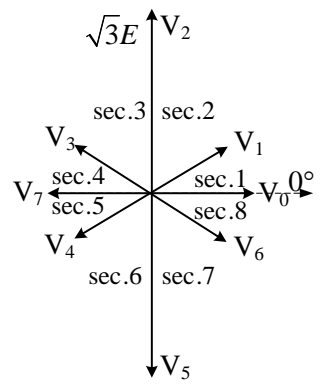

(a) Phase A fault.

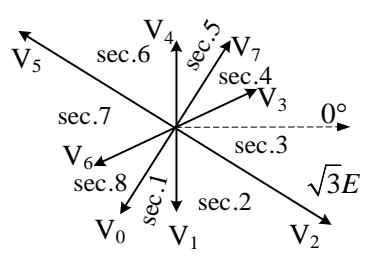

(b) Phase B fault.

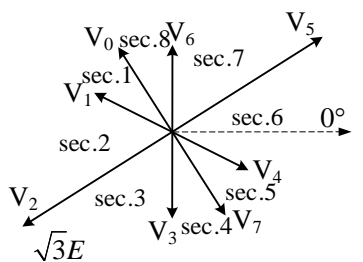

(c) Phase C fault.

Fig. 5. Voltage space vector chart.

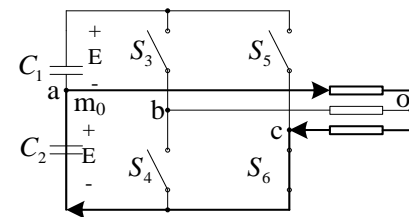

(a) $\mathrm{V}_{1}$

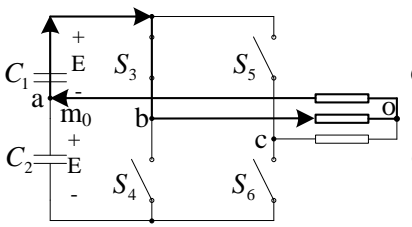

(c) V3

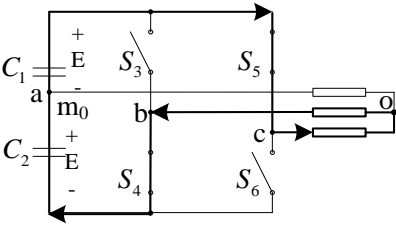

(e) V5

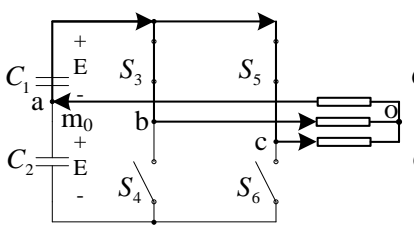

(g) V7

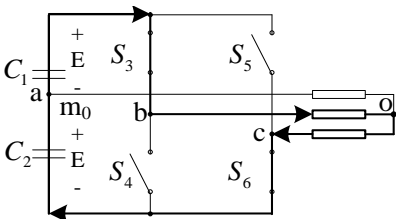

(b) $\mathrm{V}_{2}$

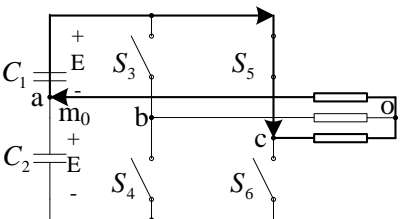

(d) V4

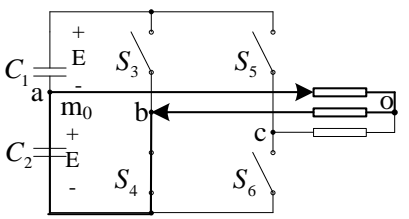

(f) V6

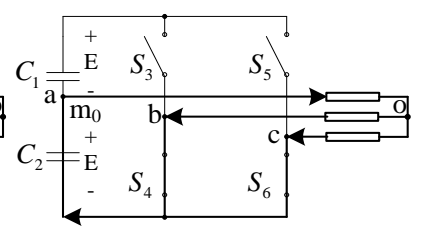

(h) V0
Fig. 6. Four-switch voltage vector topology.

Two additional voltage vectors $V_{0}$ and $V_{7}$ that are unused in the conventional four-switch PWM scheme are included in the voltage vector selection table to obtain torque in the two-phase conduction four-switch BLDCM drive. The reason for this scenario is that the current will always attempt to flow in Phase A because of its back-EMF and the absence of switches that control its current. Thus, a distorted current flows in phases A, B, and C. Therefore, the voltage space vectors of phases $\mathrm{B}$ and $\mathrm{C}$ conduction can be difficult to
TABLE II

Four-Switch Voltage SPace Vector Selection for the BLDCM DRIVE

$\tau_{i} \quad$ sec.1 sec.2 sec.3 sec.4 sec.5 sec.6 sec.7 sec.8

\begin{tabular}{lllllllll}
\hline 1 & V1 & V2 & V3 & V7 & V4 & V5 & V6 & V0 \\
0 & V0 & V1 & V2 & V3 & V7 & V4 & V5 & V6 \\
\hline
\end{tabular}

implement for the BLDCM drive unless several modifications are applied to overcome the back-EMF effect of Phase $\mathrm{A}$ in these conditions. $V_{0}$ and $V_{7}$ are then used to compensate for the effect of the Phase A distorted current caused by an incompletely balanced load, and selecting the right switching pattern to control the current on phases $\mathrm{B}$ and $\mathrm{C}$ independently can further lower the distorted currents on these phases and result in a smoother overall current and EM torque.

A torque ripple suppression method is proposed (Fig. 7) and explained in detail below to improve the above phenomenon.

The torque ripple suppression method controls instantaneous torque and flux to achieve high-performance operation [16], [17]. A novel voltage vector selection table must be defined for this purpose on the basis of the output states of the instantaneous stator flux magnitude hysteresis controller and EM torque hysteresis controller, as well as the equivalent sector where the instantaneous stator flux space vector is located [18], [19]. The output of the hysteresis controller for torque and flux are shown in Eqs. (2) and (3).

$$
\begin{gathered}
\tau_{\lambda}=\left\{\begin{array}{lll}
1, & \text { for } & \left|\lambda_{s}^{*}\right|-\left|\lambda_{s}\right|>\Delta \lambda_{s} / 2 \\
0, & \text { for } & \left|\lambda_{s}^{*}\right|-\left|\lambda_{s}\right|<\Delta \lambda_{s} / 2
\end{array}\right. \\
\tau_{T}=\left\{\begin{array}{lll}
1, & \text { for } & T_{e}^{*}-T_{e}>\Delta T_{e} / 2 \\
0, & \text { for } & T_{e}^{*}-T_{e}<\Delta T_{e} / 2
\end{array}\right.
\end{gathered}
$$

where $\Delta \lambda_{s}$ is the stator flux hysteresis bandwidth, and $\Delta T_{e}$ is the torque hysteresis bandwidth. Given the eight available switching states in FSTPI, the stator flux plane is divided into eight different sectors. An optimized lookup table (Table III) and the stator flux position information defined in the equivalent sector are used to translate these two control states into the inverter gate drive signals [20], [21].

How to eliminate flux disturbance and torque pulsation when the rotor position is in Sector 2 and in the CCW direction is explained in the following section.

Case $\mathrm{A}\left(\tau_{T}=\tau_{\lambda}=1\right): T_{e}^{*}-T_{e}>\Delta T_{e} / 2$ and $\left|\lambda_{s}^{*}\right|-\left|\lambda_{s}\right|>\Delta \lambda_{s} / 2$ should increase the flux and torque; $V 2$ is also selected.

Case B $\left(\tau_{T}=1\right.$ and $\left.\tau_{\lambda}=0\right): T_{e}^{*}-T_{e}>\Delta T_{e} / 2$ and $\left|\lambda_{s}^{*}\right|-\left|\lambda_{s}\right|<\Delta \lambda_{s} / 2$ should increase the torque and decrease the flux; V4 is also selected.

Case C $\left(\tau_{T}=0\right.$ and $\left.\tau_{\lambda}=1\right)$ : this case contrasts with Case B and selects $V 1$.

Case $\mathrm{D}\left(\tau_{T}=0\right.$ and $\left.\tau_{\lambda}=0\right)$ : this case contrasts with Case A and selects V5. 


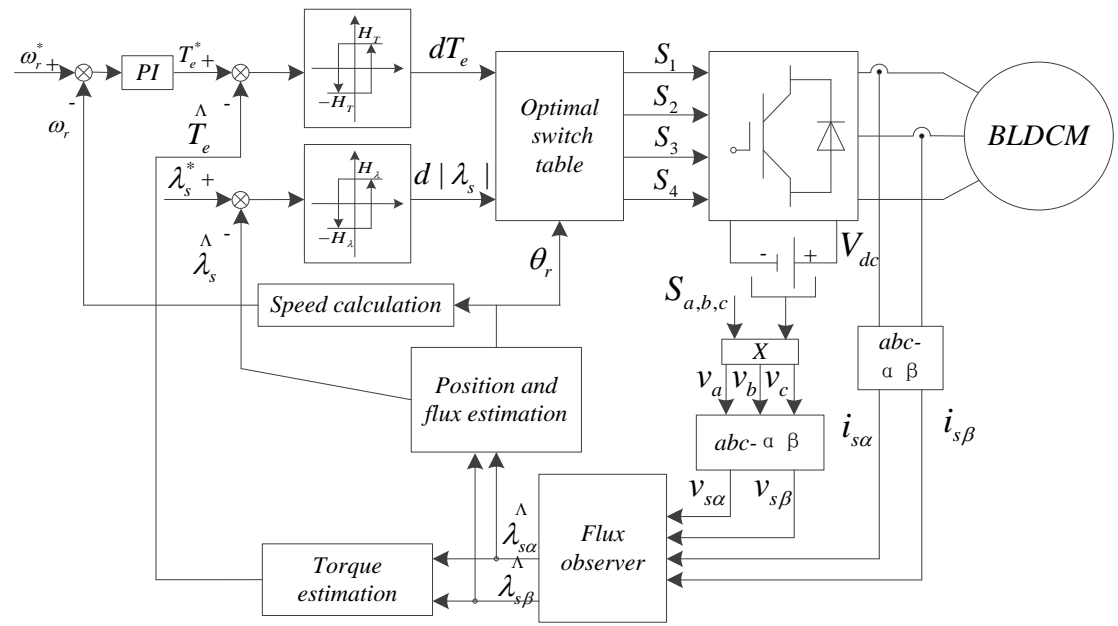

Fig. 7. Schematic of the BLDCM control system.

TABLE III

Voltage Vector SELEction IN Sectors II AND V FOR the FOUR-SWITCH BLDCM DRIVE (CCW)

\begin{tabular}{cccccccccc}
\hline$\tau_{T}$ & $\tau_{\lambda}$ & sec.1 & sec.2 & sec.3 & sec.4 & sec.5 & sec.6 & sec.7 & sec.8 \\
\hline \multirow{2}{*}{1} & 1 & V1 & V2 & V3 & V7 & V4 & V5 & V6 & V0 \\
& 0 & V7 & V4 & V5 & V6 & V0 & V1 & V2 & V3 \\
& 1 & V0 & V1 & V2 & V3 & V7 & V4 & V5 & V6 \\
0 & 0 & V4 & V5 & V6 & V0 & V1 & V2 & V3 & V7 \\
\hline
\end{tabular}

The abovementioned process can also be analyzed when the rotor position is in other sectors.

Similarly, the voltage vector selection table can be concluded when the fault occurs in other phases.

In addition, the rotor direction is important in defining the specific switching pattern. If the rotor direction is CW, then the above claims are reversed.

This technique has the advantage of not requiring an integration step in the estimation calculation, which removes problems associated with drift and integral windup [22], [23]. However, it does not rely on the motor parameters and an expensive position sensor.

A novel stator flux observation method is proposed and the observation principle is analyzed in detail in the next section.

\section{FLUX CALCULATION}

\section{A. Flux Observation}

The flux equation of BLDCM under the $\alpha \beta$ two-phase static coordinate system can be expressed as follows:

$$
d \lambda_{\mathrm{s}} / d t=u_{\mathrm{s}}-R i_{\mathrm{s}}
$$

where $\lambda_{s}=\left[\begin{array}{ll}\lambda_{s \alpha} & \lambda_{s \beta}\end{array}\right]^{T}$ is the stator flux matrix, $u_{s}=\left[\begin{array}{ll}u_{s \alpha} & u_{s \beta}\end{array}\right]^{T}$ is the stator voltage matrix, $i_{s}=\left[\begin{array}{ll}i_{s \alpha} & i_{s \beta}\end{array}\right]^{T}$, is the stator current matrix, and $R$ is the stator resistance.

The sliding surface is defined as follows:

$$
S(X)=\tilde{i}=i-\hat{i}
$$

The BLDCM flux sliding-mode observer equation is as follows:

$$
\begin{gathered}
d \hat{\lambda_{s}} / d t=u_{s}-R \hat{i}_{s}+K \tilde{i}_{s}+G_{S W} \operatorname{sign}\left(\tilde{i_{s}}\right) \\
\hat{i}_{s}=\Theta^{-1} L^{-1} \Theta \hat{\lambda}_{s}+\frac{\lambda_{m}}{L_{s}}\left(\begin{array}{c}
\cos \hat{\theta}_{r} \\
\operatorname{s} \\
\sin \hat{\theta}_{r}
\end{array}\right)
\end{gathered}
$$

where

$$
\Theta=\left[\begin{array}{cc}
\cos \hat{\theta}_{r} & -\sin \hat{\theta}_{r} \\
\hat{\Lambda} & \hat{\Lambda}^{\prime}
\end{array}\right] \quad ; \quad L=\operatorname{diag}\left(\begin{array}{ll}
L_{s} & L_{s}
\end{array}\right) \quad \text {; }
$$

$K=k_{1} I+k_{2} H$, where $I$ is the unit matrix, $H=\left(\begin{array}{cc}0 & -1 \\ 1 & 0\end{array}\right)$, and the symbol "^" is the estimated value of the corresponding variable. $G_{S W}\left(G_{S W}=g I\right)$ is the sliding mode gain matrix, where $g$ is a positive constant, $\lambda_{m}$ is the flux amplitude of the rotor permanent magnet, and $\theta_{r}$ is the rotor position angle.

The rotor position equation is as follows:

$$
\hat{\theta}_{r}=\tan ^{-1}\left(\lambda_{s \alpha}^{\Lambda} / \lambda_{s \beta}^{\Lambda}\right)
$$

The EM torque equation is as follows:

$$
T_{e}=\frac{3 P}{4}\left[\frac{d \lambda_{s \alpha}}{d \hat{\theta}_{r}} i_{s \alpha}^{\Lambda}+\frac{d \lambda_{s \beta}^{\Lambda}}{d \hat{\theta}_{r}} i_{s \beta}{ }^{\Lambda}\right]
$$

\section{B. Speed Calculation}

Eq. (9) can be obtained from Eq. (7) as follows:

$$
\hat{\theta}_{r}=\frac{1}{s+\omega_{c}} \hat{\omega}_{r}+\frac{\omega_{c}}{s+\omega_{c}} \hat{\theta}_{r}
$$

where $\omega_{c}$ is the cut-off frequency.

The first-order low-pass filter in Eq. (9) is adopted to replace the integrator, and it can improve the noise in the speed calculation. Fig. 8 shows the speed calculation method.

\section{Stability Analysis}

Suppose that the current error is provided by the following: 


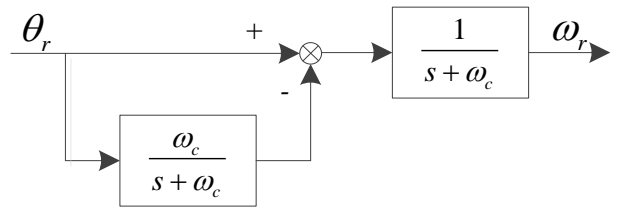

Fig. 8. Speed calculation.

$$
\tilde{i}_{s}=\Theta^{-1} L^{-1} \Theta \tilde{\lambda}_{s}
$$

The dynamic error of flux estimation is as follows:

$$
\tilde{\lambda}_{s}=-\tilde{R}_{i_{s}}-K \tilde{i}_{s}-G_{S W} \operatorname{sign}\left(\tilde{i_{s}}\right)
$$

where $\stackrel{\tilde{R}}{R}=R-\stackrel{\Lambda}{R}$.

A Lyapunov candidate function is defined as follows:

$$
V=\frac{1}{2}\left(\tilde{\lambda}_{s}^{T} \Theta^{-1} L^{-1} \Theta \tilde{\lambda}_{s}+a \tilde{R}^{2}\right) \tilde{\lambda}_{s}>0
$$

and

$$
\dot{V}=\tilde{\lambda}_{s}^{T} \Theta^{-1} L^{-1} \Theta \dot{\tilde{\lambda}}+\omega_{r} \tilde{\lambda}_{s}^{T} \Theta^{-1} L^{-1} J \Theta \tilde{\lambda}_{s}-a \dot{\tilde{R}} \tilde{R}
$$

The following equation is derived when Eq. (10) is substituted into Eq. (12):

$$
\begin{aligned}
& \dot{V}=-\tilde{i}_{s} \Theta^{-1}\left[k_{1} I+H\left(k_{2} I-\omega_{r} L\right)\right] \Theta \tilde{i}_{s}- \\
& \tilde{R}\left(i_{s \alpha} \tilde{i}_{s \alpha}+i_{s \beta} \tilde{i_{s \beta}}+a \tilde{R}\right)-\tilde{i}_{s} G_{S W} \operatorname{sign}\left(\tilde{i_{s}}\right)
\end{aligned}
$$

$\dot{V}<0$ is set for the global asymptotic stability. Thus, the following equations can be deduced:

$$
\begin{gathered}
{\left[k_{1} I+H\left(k_{2} I-\omega_{r} L\right)\right]>0} \\
\dot{\tilde{n}} \\
i_{s \alpha} \tilde{i_{s \alpha}}+\dot{i}_{s \beta} \tilde{i_{s \beta}}+a \stackrel{R}{R}=0 \\
\tilde{i_{s}} G_{s W} \operatorname{sign}\left(\tilde{i_{s}}\right)>0
\end{gathered}
$$

If Eqs. (15)-(17) are satisfied, then the control system is stable.

\section{OBSERVER PARAMETER SELECTION}

To stabilize the system, all the eigenvalues of (15) should be in the right half-plane and be through the pole-zero placements to select $k_{1}$ and $k_{2}$.

The classical approach to observer gain selection is to design the observer poles proportional to the motor poles [24]. This approach requests the proportion coefficient $\mathrm{k}>1$ and allows the observer to be dynamically faster than the motor.

The motor pole is the function of its speed, which is expressed as follows:

$$
p\left(\omega_{r}\right)=-R / L_{s}
$$

Therefore, the eigenvalues of the observer can be described as follows:

$$
p^{\prime}\left(\omega_{r}\right)=-k R / L_{s}
$$

The observer gains $k_{1}$ and $k_{2}$ are as follows:

$$
k_{1}=k R / L_{s}
$$

$$
k_{2}=\omega_{r} L_{s}
$$

where $k>0$ and $k=10$ in the actual operation after multiple tests.

Given that the actual speed $\omega_{r e}$ is unavailable, the estimated speed is used instead.

Eq. (22) can be derived from Eq. (17).

$$
g\left|\tilde{i_{s \alpha}}\right|+g\left|\tilde{i_{s \beta}}\right|>0
$$

Eq. (22) determines that $g>0$.

Eq. (23) can be derived from Eq. (16) as follows:

$$
R=-\frac{1}{a} \int_{0}^{T}\left(i_{s \alpha} \tilde{i}_{s \alpha}+i_{s \beta} \tilde{i}_{s \beta}\right) d t+R_{0}
$$

where $R_{0}$ is the initial value of stator resistance, and $T$ is the switching period.

The BLDCM flux sliding-mode observer equation in steady state is as follows:

$$
u_{s}=R \hat{i}_{s}-K \tilde{i}_{s}-G_{S W} \operatorname{sign}\left(\tilde{i_{s}}\right)
$$

Eq. (25) can be obtained from Eqs. (20), (21), (23), and (24).

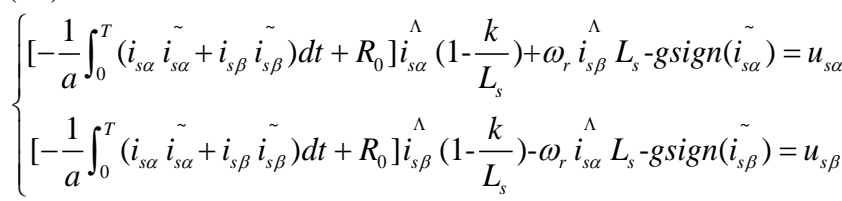

We can obtain the values of $a$ and $g$ from Eq. (25) as follows:

$$
\begin{aligned}
& g=\frac{\hat{i}_{s \beta} u_{s \alpha}-i_{s \alpha} u_{s \beta}-\omega_{r}\left(i_{s \beta}{ }^{2}+i_{s \alpha}^{{ }^{2}}\right) L_{s}}{\Lambda_{s \alpha} \operatorname{sign}\left(\tilde{i_{s \beta}}\right)-i_{s \beta} \operatorname{sign}\left(i_{s \alpha}\right)}
\end{aligned}
$$

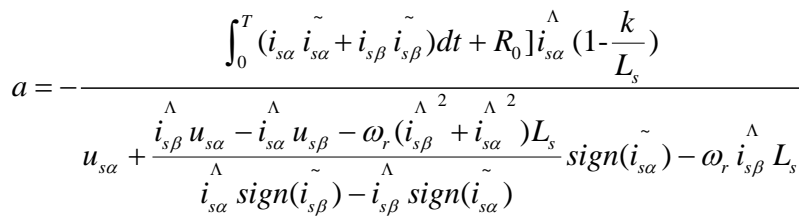

We can obtain $a$ and $g$ from Eqs. (26) and (27).

The stator voltage can be used in the flux observation process, but $v_{\alpha}$ and $v_{\beta}$ are reconstructed from the DC bus voltage $V_{d c}$ and switching status. Any DC measurement error, switch voltage, and dead-time voltage are reflected in both $v_{\alpha}$ and $v_{\beta}$, especially in low-speed performance. Fig. 9 shows that the torque and flux estimation error curves are provided under the given speed of $1000 \mathrm{rpm}$ and $3 \mathrm{Nm}$ load conditions. Fig. 9(a) clearly shows that the operational performance of control system is poor.

The effects of the DC offset can be alleviated by introducing a variable PI component in the regulation coefficient as follows:

$$
K=k_{1} I+\left[k_{2}+\left(\frac{\omega_{r \max }-\omega_{r}}{\omega_{r \max }}+k_{c}\right) \frac{1}{s}\right] H
$$

where $\omega_{\text {rmax }}$ is the maximum speed, and $k_{c}$ is a small positive constant equal to 0.5 in the actual operation. 

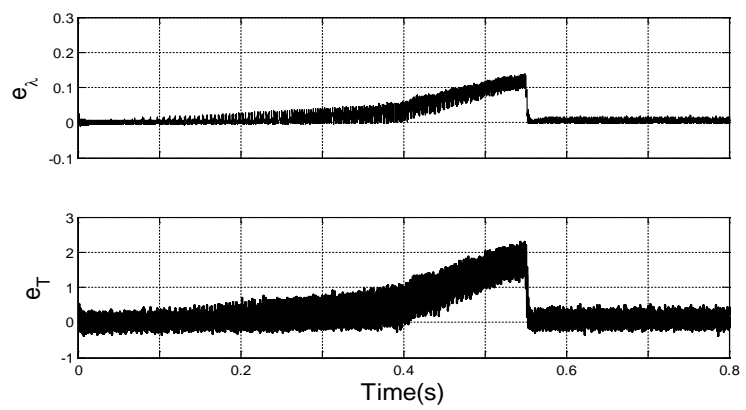

(a) Before compensation.
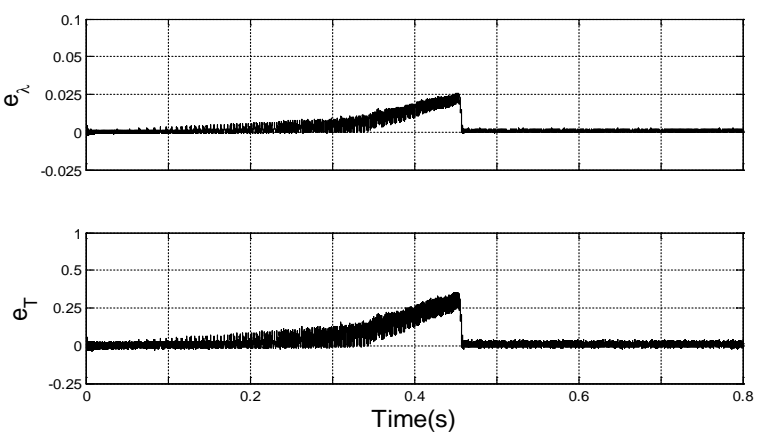

(b) After compensation.

Fig. 9. Torque and flux estimation error curve under $1000 \mathrm{rpm}$ and $3 \mathrm{Nm}$ load.

TABLE IV

PARAMETERS OF THE BLDC MOTOR

\begin{tabular}{ccc||ccc}
\hline Rated torque & Te & $3 \mathrm{Nm}$ & $\begin{array}{c}\text { Stator } \\
\text { inductance }\end{array}$ & $\mathrm{L}$ & $5.22 \mathrm{mH}$ \\
\hline Rated speed & $\mathrm{n}$ & 1500 & Inertia & $\mathrm{J}$ & $0.08 \mathrm{~kg} \cdot \mathrm{m}^{2}$ \\
\hline Stator resistance & $\mathrm{Rs}$ & $5 \Omega$ & Pole pairs & Pn & 2 \\
\hline Switching cycle & $\mathrm{T}$ & $5 \times 10^{-5} \mathrm{~s}$ & & & \\
\hline
\end{tabular}

The advantages of Eq. (28) is that the function of the last item can clearly be increased, when the error is large at the beginning of the operation, or the flux error is large, especially at low-speed. With the increasing speed or decreasing flux error, the function of the last item clearly weakens and the overshoot is limited. The result after compensation is shown in Fig. 9(b).

\section{EXPERIMENTAL RESULTS}

The control system structure of BLDCM is shown in Fig. 7. The BLDCM control system was established with Intelligent Power Module devices, and dsPIC6010A was used as the main controller. The BLDCM parameters are shown in Table IV. Experimental results are shown in Figs. 10, 11, and 12. Figs. 10 and 11 show that the torque is changed from $3 \mathrm{Nm}$ to $1 \mathrm{Nm}$ at low speed (20 rpm) and high speed (1500 rpm) respectively. Fig. 12 shows the experimental results when $S_{1}$ is from the normal operation mode to the short-circuit mode at $0.8 \mathrm{~s}$, and the target speed and torque are $1500 \mathrm{rpm}$ and 3 $\mathrm{Nm}$ respectively.
Figs. 10(a) to 10(d) show that the flux error is larger in the startup process, and the flux error is approximately stable with speed into the steady state in the proposed method and DCC. However, the change in torque has little impact on the flux in the proposed method and DCC. A smoother flux curve and smaller flux error are also obtained for the voltage vector selection table. The stator resistance online estimate (Fig. 10e) and DC voltage compensation are introduced in proposed method. Thus, the proposed flux observer can provide an accurate flux size and position information for the method in the low-speed range.

Figs. 10(f) to 10(i) clearly show that the proposed method can improve current distortion caused by the uncontrolled phase, and the current and back-EMF response speeds are faster than that of traditional DCC in the low-speed range.

Figs. 10(j) and $10(\mathrm{k})$ show that the proposed method can improve torque pulsation and have better dynamic and static performance characteristics of the torque compared with those of traditional DCC in the low-speed range.

Figs. 10(l) and 10(m) show that the proposed method can improve speed pulsation and has better dynamic and static performance characteristics of the speed compared with those of traditional DCC in the low-speed range.

Figs. 11(a) to 11(d) show that the flux error increased with the increasing speed, whereas it is relatively stable with speed into the steady state in the proposed method and DCC. However, the change in torque also has little impact on flux in the proposed method and DCC. A smoother flux curve, smaller flux error, and shorter transient process of flux are obtained for the voltage vector selection table. The stator resistance online estimate (Fig. 11e) and DC voltage compensation are introduced in the proposed method. Thus, the proposed flux observer can provide an accurate flux size and position information for the method in the high-speed range.

Figs. 11(f) to 11(i) show that the proposed method can improve current distortion caused by the uncontrolled phase, and the current and back-EMF response speed are faster than that of traditional DCC in the high-speed range.

Figs. 11(j) and 11(k) show that the proposed method can effectively improve torque pulsation and has better dynamic and static performance characteristics of torque compared with those of the traditional DCC in the high-speed range.

Figs. 11(l) and 11(m) show that the proposed method can effectively improve speed response and has better dynamic and static performance characteristics of the speed compared with those of traditional DCC in the high-speed range.

Figs. 12(a) to 12(d) show that the transient process from normal operation mode to fault tolerance mode is approximately $50 \mathrm{~ms}$, whereas the proposed method can realize fault tolerance of the inverter when a fault occurs in one bridge. 


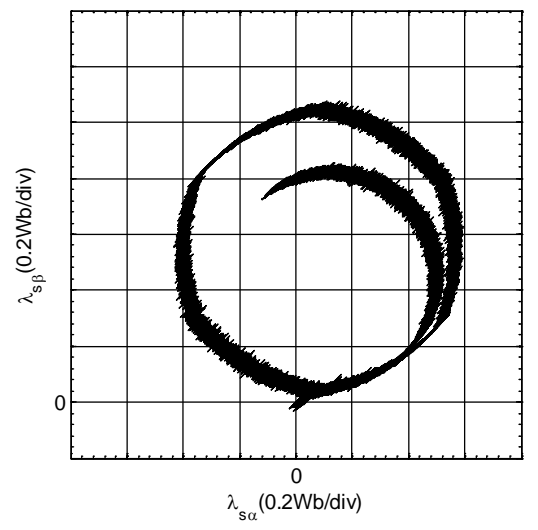

(a) Flux observation curve under the proposed method.

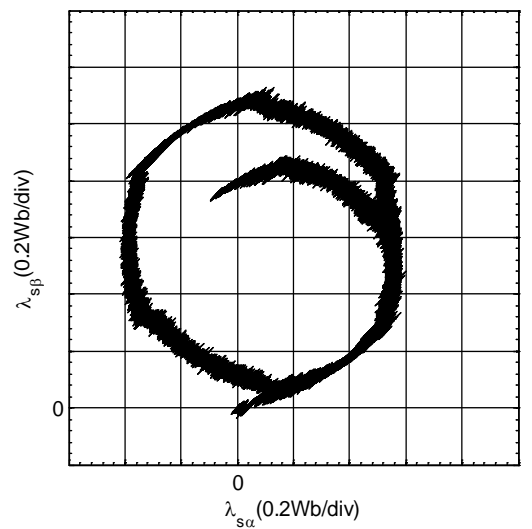

(b) Flux observation curve under DCC.

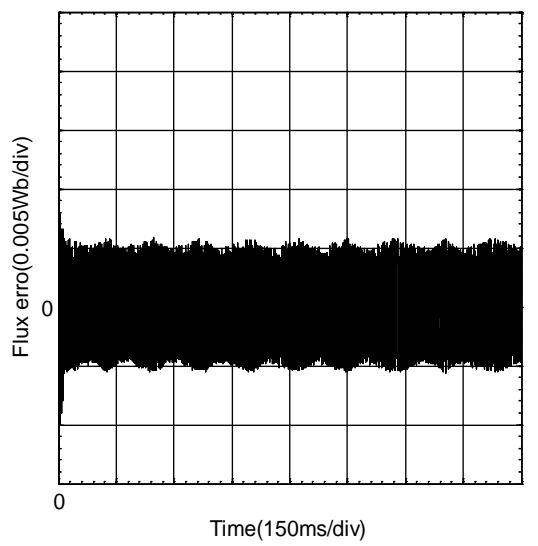

(c) Flux error curve under the proposed method.

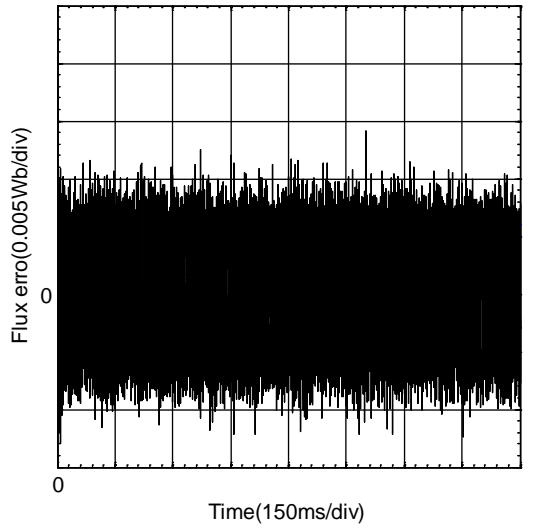

(d) Flux error curve under DCC.

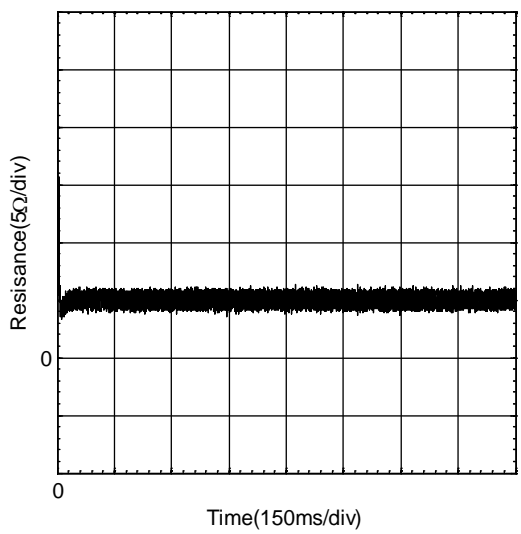

(e) $R$ estimation curve under the proposed method.

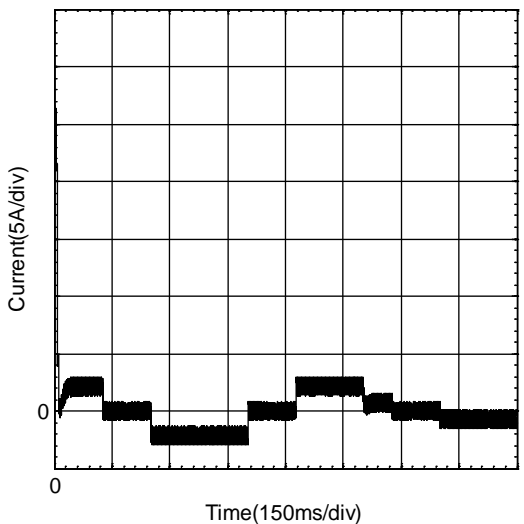

(f) Current response curve under the proposed method.

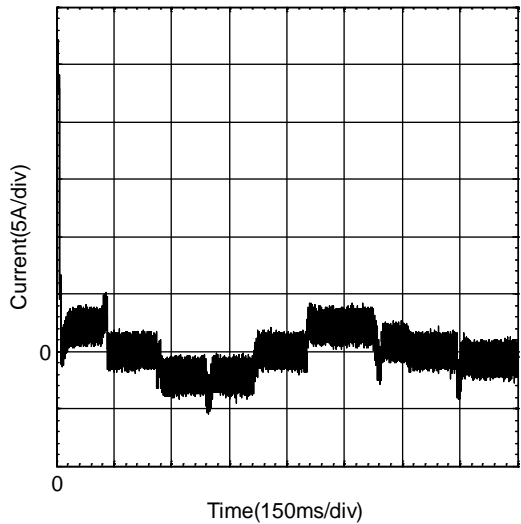

(g) Current response curve under DCC.

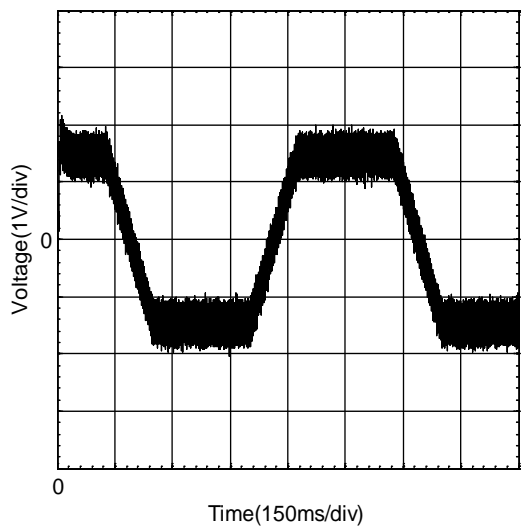

(h) Back-EMF curve under the proposed method. 


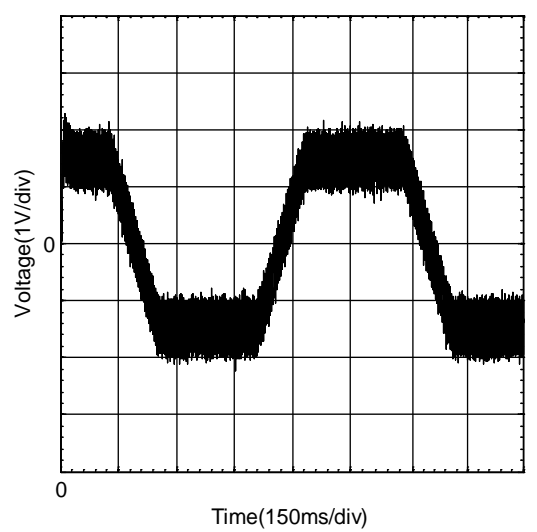

(i) Back-EMF curve under DCC.

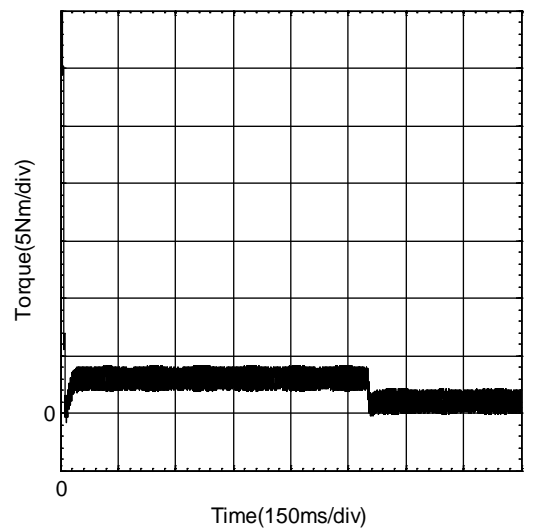

(j) Torque response curve under the proposed method.

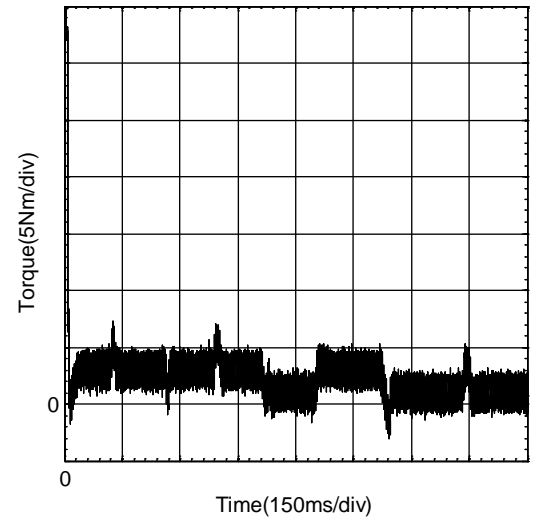

(k) Torque response curve under DCC.

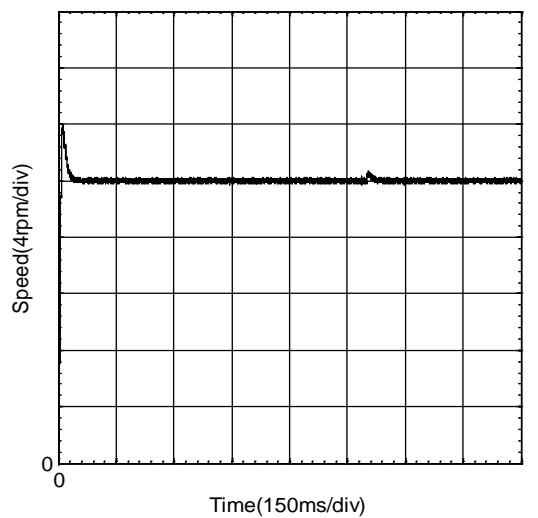

(l) Speed response curve under the proposed method.

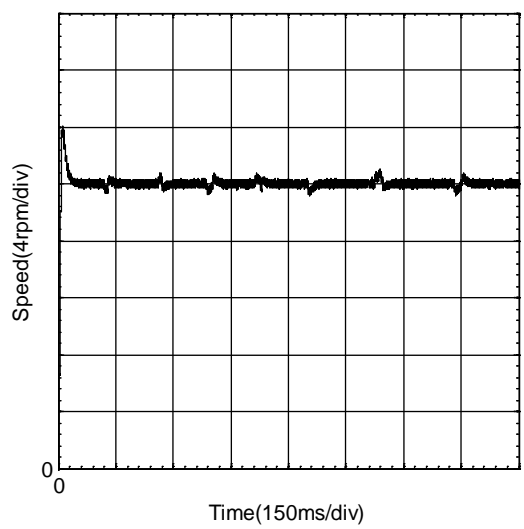

(m) Speed response curve under DCC.

Fig. 10. Experimental results I.

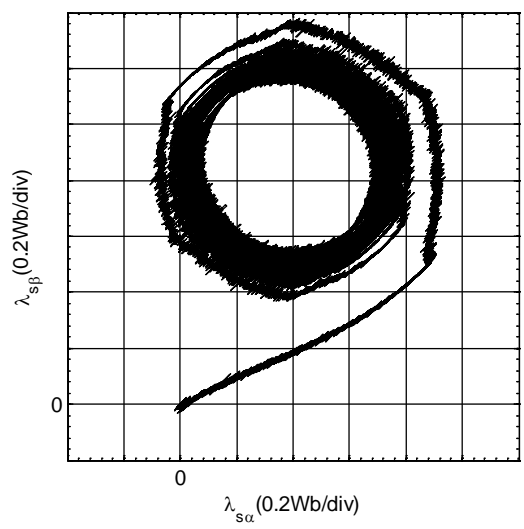

(a) Flux observation curve under the proposed method.

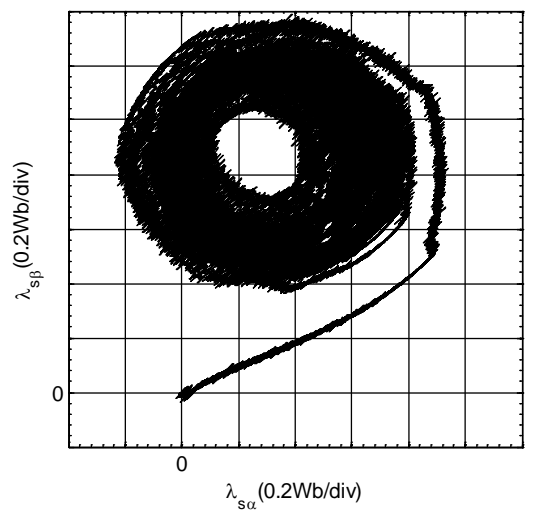

(b) Flux observation curve under DCC.

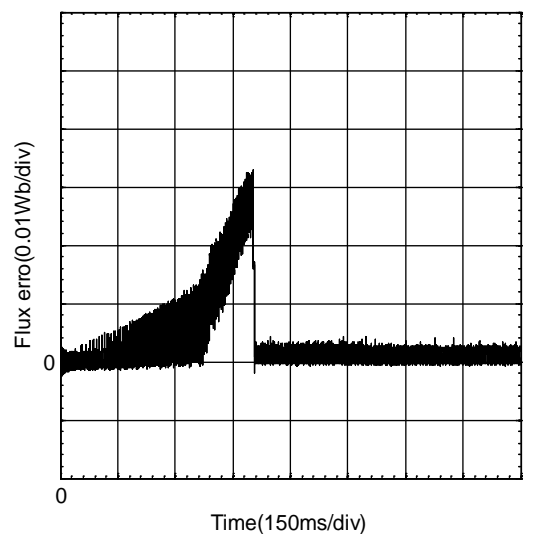

(c) Flux error curve under the proposed method. 


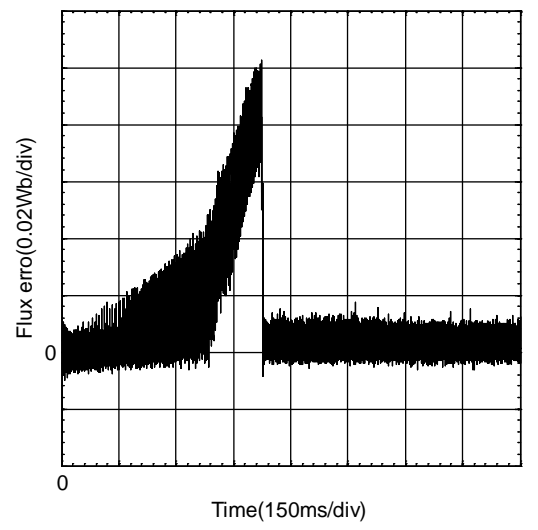

(d) Flux error curve under DCC.

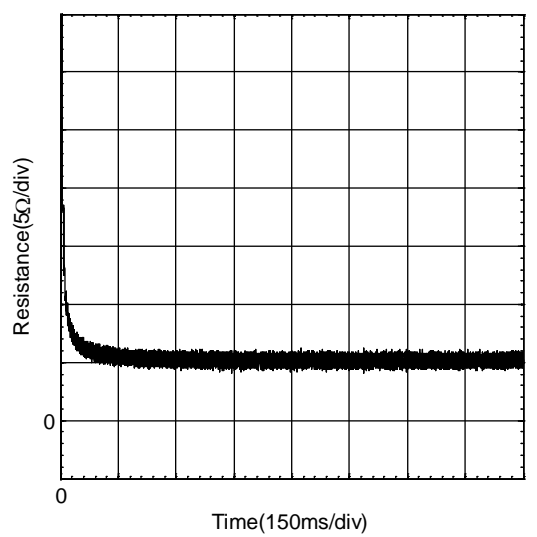

(e) $R$ estimation curve under the proposed method.

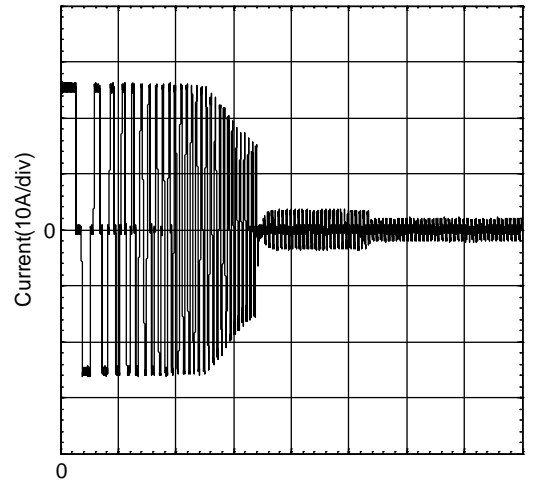

Time(150ms/div)

(f) Current response curve under the proposed method.

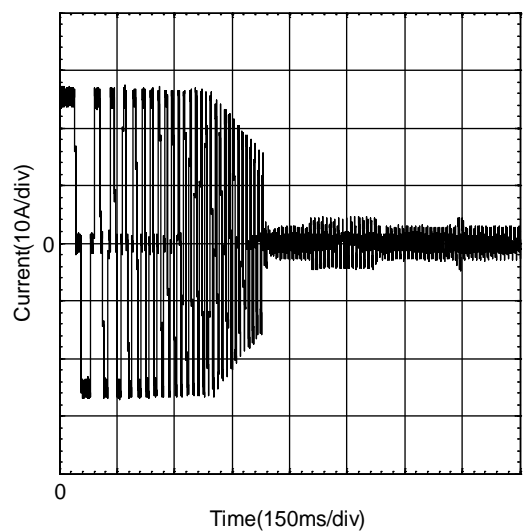

(g) Current response curve under DCC.

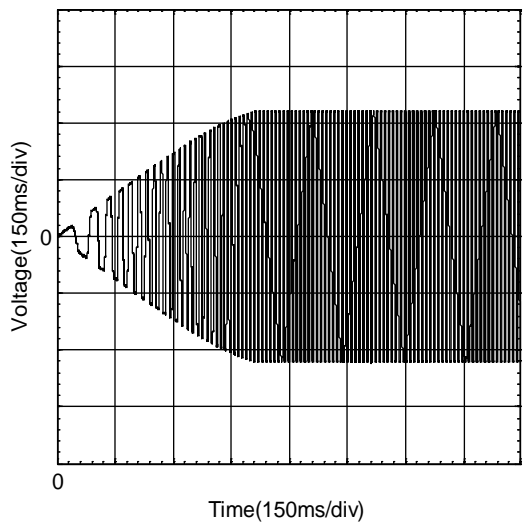

(h) Back-EMF curve under the proposed method.

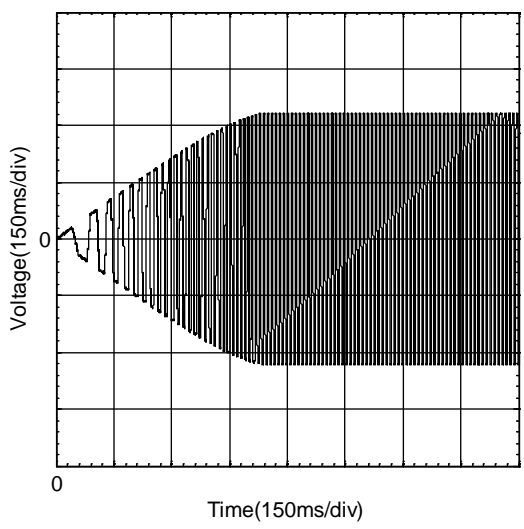

(i) Back-EMF curve under DCC.

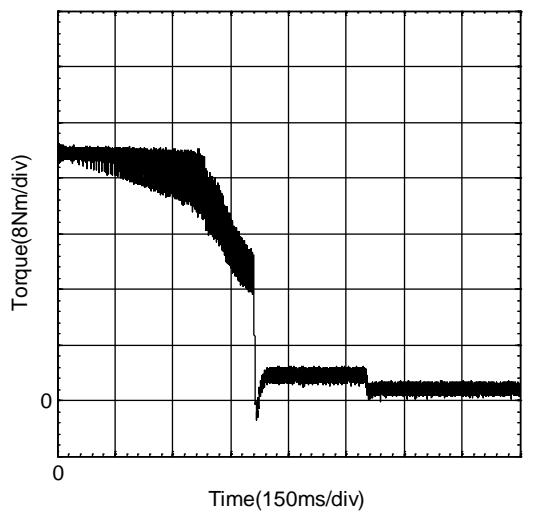

(j) Torque response curve under the proposed method.

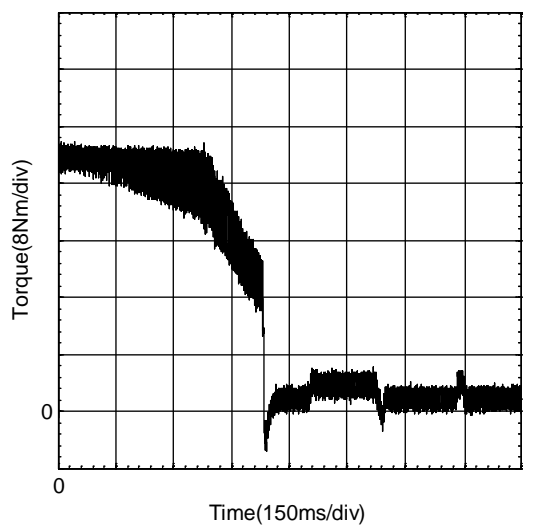

(k) Torque response curve under DCC. 


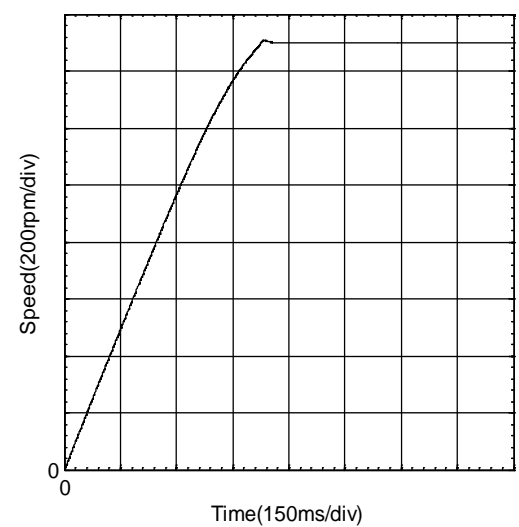

(l) Speed response curve under the proposed method.

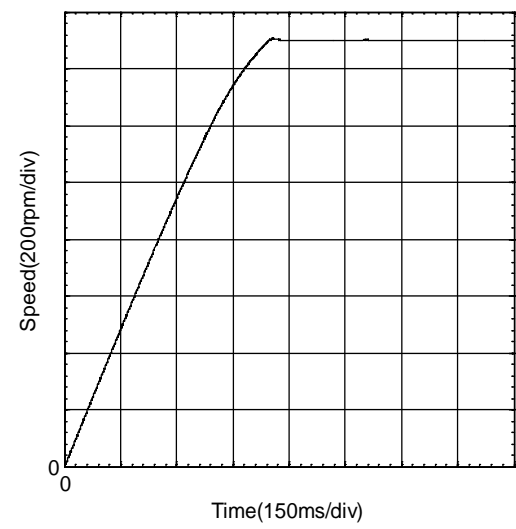

(m) Speed response curve under DCC.

Fig. 11. Experimental results II.

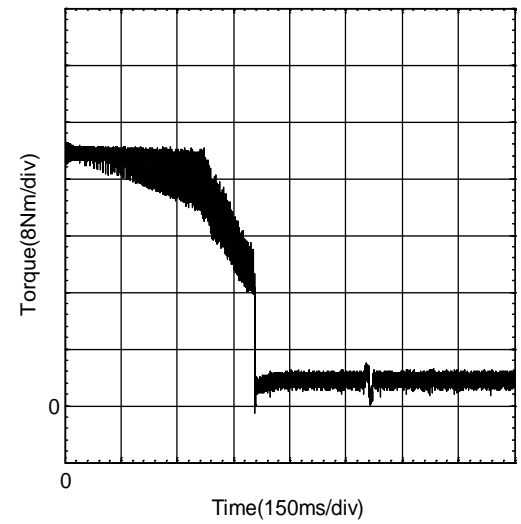

(a) Torque response curve.

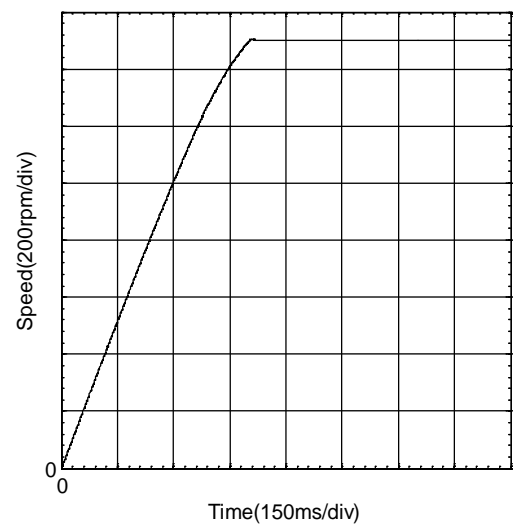

(b) Speed response curve.

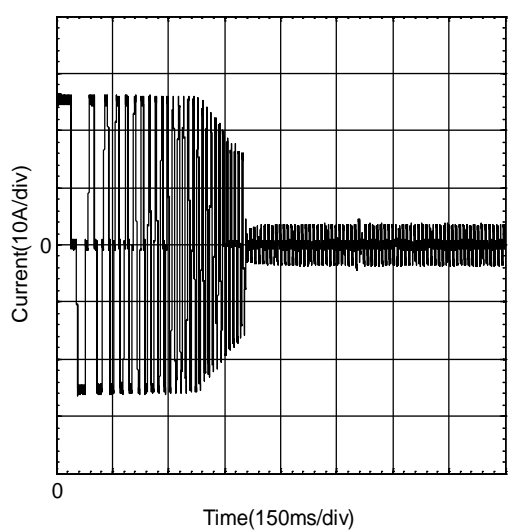

(c) Current response curve of the non-fault phase.

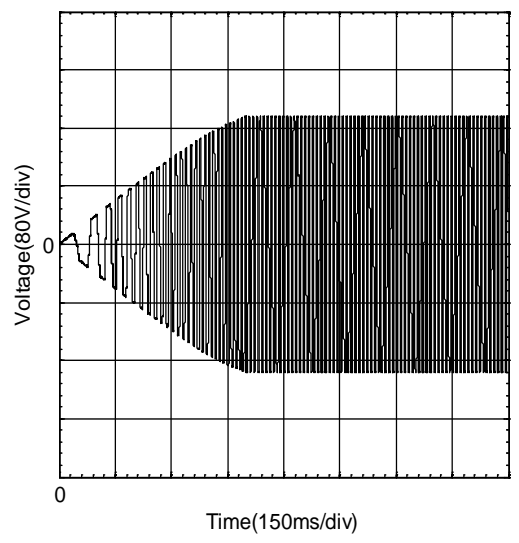

(d) Back-EMF response curve.

Fig. 12. Experimental results III

\section{CONCLUSION}

This paper presents a novel inverter fault-tolerant and torque ripple suppression control method. A voltage vector selection table and a stator flux observer for torque ripple suppression are proposed in this method. The flux observer does not require speed adaptation and is unsusceptible to speed estimation errors, especially at low speed. The stability of the proposed observer is proven by the Lyapunov stability analysis. A novel stator resistance estimator is incorporated into the method to compensate for the effects of stator resistance variation. The effects of DC measurement offsets are mitigated by incorporating an integral compensating term in the observer gain. The proposed flux observer can deliver high performance over a wide speed range, including low speeds. Thus, current distortion and torque pulsation are effectively improved, and the response speed of torque and speed are significantly improved.

The proposed method can also be used in servo control for BLDCMs.

\section{ACKNOWLEDGMENT}

This work was supported by the Universities Science and Technology Fund Planning Project of Tianjin (20130419), the National Science and Technology Support Plan 
(2013BAJ09B03), and Tianjin Research Program of Application Foundation and Advanced Technology (15JCQNJC04500).

\section{REFERENCES}

[1] S. De, M. Rajne, S. Poosapati, C. Patel, and K. Gopakumar, "Low-inductance axial flux BLDC motor drive for more electric aircraft,” IET Power Electronics, Vol. 5, No. 1, pp. 124-133, Jan. 2012.

[2] H.-W. Kim, K.-T. Kim, Y.-S. Jo, et al, “Optimization methods of torque density for developing the neodymium free SPOKE-type BLDC motor,” IEEE Trans. Magn., Vol. 49, No. 5, pp.2173-2176, May 2013.

[3] D. K. Kastha and B. K. Bose, "Investigation of fault modes of voltage-fed inverter system for induction motor drive,” IEEE Trans. Ind. Appl., Vol. 30, No. 4, pp. 10281038, Aug. 1994.

[4] M. Khan and M. A. Rahman, "Development and implementation of a novel fault diagnostic and protection technique for IPM motor drives," IEEE Trans. Ind. Electron., Vol. 56, No. 1, pp. 85-92, Jan. 2009.

[5] B.-K. Lee, T.-H. Kim, and M. Ehsani, "On the feasibility of four-switch three-phase BLDC motor drives for low cost commercial applications: Topology and control," IEEE Trans. Power Electron., Vol. 18, No. 1, pp. 164-172, Jan. 2003.

[6] J.-H. Lee, T.-S. Kim, and D.-S. Hyun, “A study for improved of speed response characteristic in four-switch three-phase BLDC motor," in Proc. IEEE Ind. Electron. Soc. Conf., pp. 1339-1343, 2004.

[7] S.-H. Park, T.-S. Kim, S.-C. Ahn, D.-S. Hyun, “A simple current control algorithm for torque ripple reduction of brushless DC motor using four-switch three-phase inverter," 34th Annual Conference on IEEE Power Electronics Specialist, PESC 2003, pp. 574-579, Jun. 2003.

[8] B. K. Lee, T. H. Kim, and M. Ehsani, "On the feasibility of four-switch three-phase BLDC motor drives for low cost commercial applications: topology and control,” IEEE Trans. Power Electron., Vol. 18, No. 1, pp. 164-172, Jan. 2003.

[9] S. J. Park, H. W. Park, M. H. Lee, and F. Harashima, “A new approach for Minimum torque ripple maximum efficiency control of bldc motor," IEEE Trans. Ind. Electron., Vol. 47, No. 1, pp. 109-114, Feb. 2000.

[10] J. Fang, X. Zhou, and G. Liu, "Precise accelerated torque control for small inductance brushless DC motor," IEEE Trans. Power Electron., Vol. 28, No. 3, pp. 1400-1412, Mar. 2013.

[11] P. Damodharan and K. Vasudevan, "Sensorless brushless DC motor drive based on the zero-crossing detection of back electromotive force (EMF) from the line voltage difference,” IEEE Trans. Energy Convers., Vol. 25, No. 3, pp. 661-668, Sep. 2010.

[12] L. de Lillo, L. Empringham, P. W. Wheeler, S. Khwan-on, C. Gerada, M. N. Othman, and X. Huang, "Multiphase power converter drive for fault-tolerant machine development in aerospace applications," IEEE Trans. Ind. Electron., Vol. 57, No. 2, pp. 575-583, Feb. 2010.

[13] X. Huang, A. Goodman, C. Gerada, Y. Fang, and Q. Lu, "A single sided matrix converter drive for a brushless DC motor in aerospace applications," IEEE Trans. Ind.
Electron., Vol. 59, No. 9, pp. 3542-3552, Sep. 2012.

[14] J. Kim, J. Hong, and K. Nam, “A current distortion compensation scheme for four-switch converters," IEEE Trans. Power Electron., Vol. 24, No. 4, pp. 1032-1040, Apr. 2009.

[15] M. B. de Rossiter Corrêa, C. B. Jacobina, E. R. C. da Silva, and A. M. N. Lim, "A general PWM strategy for four-switch three-phase inverters," IEEE Trans. Power Electron., Vol. 21, No. 6, pp.1618-1627, Nov. 2006.

[16] C.-T. Lin, C.-W. Hung, and C.-W. Liu, "Position sensorless control for four-switch three-phase brushless DC motor drives,” IEEE Trans. Power Electron., Vol. 23, No. 1, pp. 438-444, Jan. 2008.

[17] C. Xia, Z. Li, and T. Shi, "A control strategy for four-switch three phase brushless dc motor using single current sensor,” IEEE Trans. Ind. Electron., Vol. 56, No. 6, pp. 2058-2066, Jun. 2009.

[18] Q. Fu and H. Lin, "Sliding mode driving strategy for four-switch three-phase brushless DC motor," SICE-ICASE, International Joint Conference, pp. 696-701, Oct. 2006.

[19] Z. Q. Zhu, K. Utaikaifa, K. Hoang, Y. Liu, and D. Howe, "Direct torque control of three-phase PM brushless AC motor with one phase open circuit fault," in Proc. IEEE Int. Conf. Elect. Mach. Drives, pp. 1408-1415, May 2009.

[20] C. T. Lin, C. W. Hung, and C. W. Liu, "Sensorless control for four-switch three-phase brushless DC motor drives," in Proc. 2006 IEEE Industry Applications Conference Forty-First IAS Annual Meeting (IAS'06), Vol. 4, pp. 2049-2053, Oct. 2006.

[21] A. H. Niasar, H. Moghbeli, and A. Vahedi, "Sensorless control for four-switch, three-phase brushless DC motor drive," in Proc. 15'th Iranian Conf. on Electrical Engineering, Vol. 1, pp. 2048-2053, Oct. 2006.

[22] A. H. Niasar, A. Vahedi, and H. Moghbelli, "A novel position sensorless control of a four-switch, brushless DC motor drive without phase shifter," IEEE Trans. Power Electron., Vol. 23, No. 6, pp. 3079-3087, Nov. 2008.

[23] G. J. Su and W. McKeever, "Low-cost sensorless control of brushless DC motors with improved speed range,” IEEE Trans. Power Electron., Vol. 19, No. 2, pp. 296-302, Mar. 2004.

[24] K. Hisao, M. Kouki, and N. Takayoshi, "DSP based speed adaptive flux observer of induction motor," IEEE Trans. Ind. Appl., Vol. 29, No. 2, pp. 344-348, Mar./Apr. 1993.

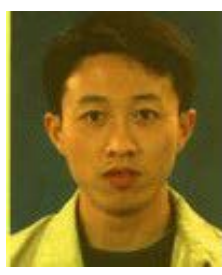

Lei Pan received his Ph.D. from HeBei University of Technology, Tianjin, China in 2014. He is currently a lecturer at Tianjin Chengjian University. His research interests are power converters and motor drives.

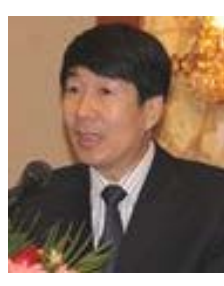

Hexu Sun received his Ph.D. from Northeastern University, Liaoning, China in 1993. He is currently a professor at HeBei University of Technology and an IEEE Senior Member. His research interests include power electronics for utility applications, electric motors, distributed power generation, and control for

engineering systems. 


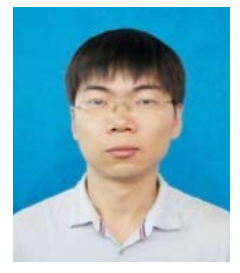

Beibei Wang received his Bachelor in Engineering and Master's degree in Electrical Engineering and Power Electronics from Liaoning Technical University, Liaoning, China, in 2006 and 2009 respectively. $\mathrm{He}$ is currently a lecturer at Tianjin Chengjian University. His research interests include power converter system and electrical motor drives.

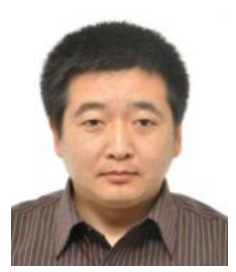

Gang Su received his Ph.D. from Nankai University, Tianjin, China, in 2005. He is currently a professor at Tianjin Chengjian University. His research interests are control of power converters and motor drives.

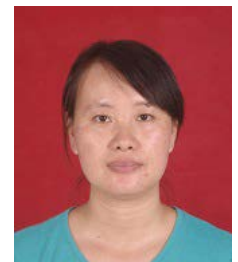

Xiuli Wang received her Master's degree from TianJin University of Technology, Tianjin, China, in 2007. She is currently a lecturer at Tianjin Chengjian University. Her research interests are intelligent control systems and emulation technique.

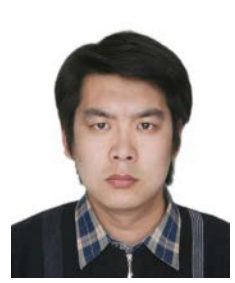

Guili Peng received his Master's degree from Southwest University of Science and Technology, Mianyang, Sichuan, China, in 2007. He is currently a lecturer at Tianjin Chenjian University. His research interests are automatic control theory and electrical and electronic technology. 